\title{
AC Impedance Spectroscopy Analysis of the Corrosion Behavior of Reinforced Concrete in Chloride Solution
}

\author{
Jinping Chen ${ }^{*}$ and Xuesong Zhang \\ College of Pipeline and Civil Engineering, China University of Petroleum, Qingdao, 266580, China \\ *E-mail: chenjp@upc.edu.cn
}

doi: $10.20964 / 2017.06 .71$

Received: 25 February 2017 / Accepted: 9 April 2017 / Published: 12 May 2017

The degradation of a reinforced concrete structure will occur with corrosion activation, which is caused by the steel rebar depassivation as a result of chloride penetration into the structure. Herein, the reinforced concrete corrosion process in a chloride solution was analyzed using AC impedance spectroscopy. The activation of the corrosion is associated with a significant impedance response decline in the capacitive part, as highlighted through multielementary analyses, SEM observations and the low-frequency region of impedance spectra.

Keywords: Impedance spectroscopy; Corrosion; Reinforced concrete; Chloride

\section{$\underline{\text { FULL TEXT }}$}

(C) 2017 The Authors. Published by ESG (www.electrochemsci.org). This article is an open access article distributed under the terms and conditions of the Creative Commons Attribution license (http://creativecommons.org/licenses/by/4.0/). 